\title{
HYPODERMOSIS IN NORTHERN SERBIA (VOJVODINA)
}

\author{
Zsolt Becskei ${ }^{1}$, Tamara Ilić ${ }^{2}$, Nataša Pavlićević ${ }^{3}$, Ferenc Kiskároly ${ }^{3}$, \\ Tamaš Petrović ${ }^{4}$, Sanda Dimitrijević ${ }^{2}$ \\ ${ }^{1}$ University of Belgrade, Faculty of Veterinary Medicine, \\ Department for Animal Breeding and Genetics, Belgrade, Serbia \\ ${ }^{2}$ University of Belgrade, Faculty of Veterinary Medicine, \\ Department of Parasitology, Belgrade, Serbia \\ ${ }^{3}$ Veterinary Specialist Institute Subotica, Subotica, Serbia \\ ${ }^{4}$ Scientific Veterinary Institute Novi Sad, Novi Sad, Serbia
}

Received 21 August 2015; Received in revised form 24 November 2015; Accepted 15 December 2015

\begin{abstract}
This paper describes the first documented case of cattle grub (hypodermosis) in Northern Serbia (Vojvodina). Subcutaneous warbles were determined in a six year old Simmental cow, at nine places along the spine. After the extirpation of larvae, based on the morphological characterisation, larvae of the third stage of Hypoderma bovis were diagnosed. The cow was administered therapeutic treatment, which had a favorable outcome, with no signs of recurrence. To the authors' best knowledge, the case described in this paper is the first documented case of hypodermosis in cattle in Northern Serbia (Vojvodina). As the climate changed in the past few decades, it is important to pursue detailed investigations of the prevalence of this parasitic myiasis, as there are few such literature data for the Southern region of Serbia. One should also not ignore the fact that species of the genus Hypoderma can cause myiasis in humans as well.
\end{abstract}

Key words: bovine, internal myiasis, oestridae, Hypoderma bovis, larval stage

\section{INTRODUCTION}

Hypodermosis is an ectoparasitic infestation, with impact both from the health and the economic aspect. The causes of this internal myiasis in cattle are larval forms of Hypoderma bovis and $H$. lineatum, and in deer, roe, and reindeer of $H$. diana, $H$. actaeon and $H$. tarandi. In addition to these 5 species, Zumpt reported two more species (H. capreola and H. moschiferi), whose names are used as synonyms for the species $H$. diana (1). An eighth species (H. sinense) was described by Pleske (2), and it was long believed that it was a synonym

Corresponding author: Dr. Zsolt Becskei, $\mathrm{PhD}$

E-mail address: beckeizolt@gmail.com

Present address: University of Belgrade, Faculty of Veterinary Medicine

Department for Animal Breeding and Genetics

Str, Bulevar Oslobodjenja 18, 11000 Belgrade, Serbia

Phone: $+381659911101,+381113615436$

Copyright: (C) 2016 Becskei Zs. This is an open-access article published under the terms of the Creative Commons Attribution License which

permits unrestricted use, distribution, and reproduction in any medium, provided the original author and source are credited.

Competing Interests: The authors have declared that no competing interests exist.

Available Online First: 4 January 2016

Published on: 15 March 2016

http://dx.doi.org/10.1515/macvetrev-2016-0072 for the species H. lineatum. Otranto used molecular analyses to prove the presence of $H$. sinense as a separate species that is parasitizing in cattle in China (3).

The biology of the warble fly is complex, since Hypoderma passes through both the ecto- and endoparasitic stages of the life cycle. The parasitic phase in domestic and wild animals lasts around one year, but the adult female of the warble fly lives in an inactive form in the external environment for several days, and during that time (in flight or upon landing on skin), it lays eggs on the host's body (4). The model of animal breeding and favorable climatic conditions pose risk factors that favor the life cycle of the parasite (5).

The disease caused by the species $H$. bovis and H. lineatum mostly occurs between $25^{\circ}$ and $60^{\circ}$ latitude in the northern hemisphere, in more than 50 countries in North America, Europe, Africa and Asia (6). The accuratee prevalence of bovine infection with these Oestridae in Europe is not known. It varies from year to year, and is conditioned upon activities by ecological factors. It is known that the 


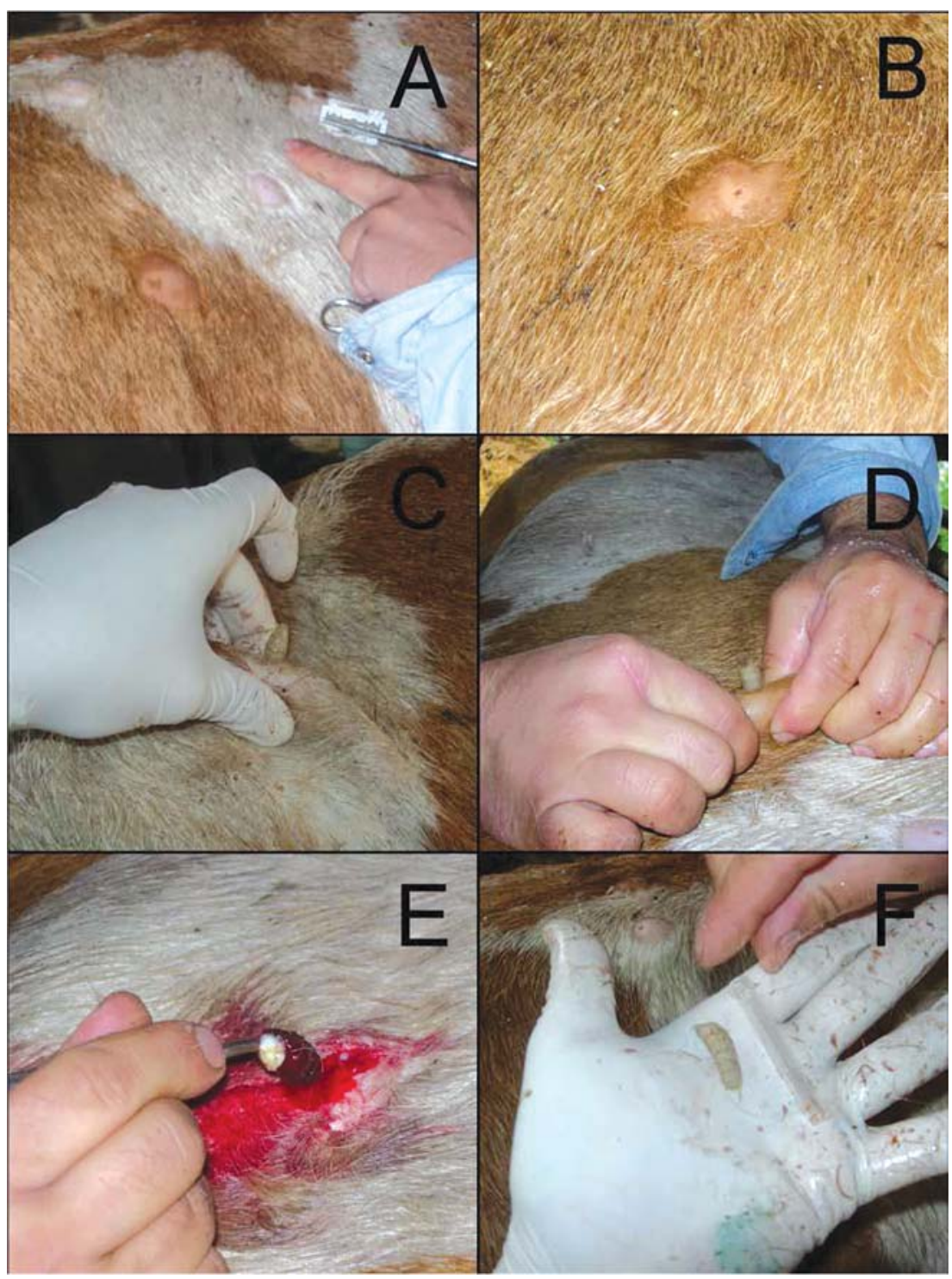

Figure 1. A. Localization of parasitic nodules along the hump; B. Cattle grub caused by $H$. bovis; C. and D. Manual extirpation of $H$. bovis larvae; E. Surgical extirpation of $H$. bovis larvae; F. Extirpated H. bovis larvae

lower temperatures in Eastern and Central Europe slow down the biological cycle of these parasites. Hypodermosis has a wide geographical distribution pattern in livestock as reported by Ahmed (7). In some cases, larvae can be found individually also in horses, donkeys, bison, sheep, and even in man $(7,8,9)$.

\section{CASE REPORT}

This paper presents a case of hypodermosis diagnosed in May 2013 in a cow from the vicinity of Subotica (the settlement of Stari Žednik). The infested animal was 6 years old and originated 130 from Southern Serbia where it was purchased in the cattle market. After being purchased, the cow was introduced to a homestead located in the epizootological territory of the North-Bačka District, where it was placed together with 10 dairy cows originating from this locality. The purchased cow was maintained in the barn, it was tethered, and it did not go out to pasture.

The owner contacted the local veterinarian when nodules were observed along the spine of the cow, and asked him to identify the cause of these changes.

Inspection and palpation established subcutaneously located nodular changes on the skin at nine points along the spine. The biggest number of established nodules was located along the hump, 
Hypodermosis in Northern Serbia (Vojvodina)

from the shoulder to the sacral part, and they were partly also distributed laterally to the left and to the right. Their dimensions ranged from 1.5 to $3.5 \mathrm{~cm}$ in diameter, and the hairs surrounding the opening of the warble were sticky with a dried secretion.

Following disinfection and removal of the hairs, the Hypoderma larvae were removed from the warbles. After removal of the larvae from the warbles, they were conserved in $70 \%$ alcohol. After the surgical procedures, the animal was treated with a combination of antibiotics (amoxicillin: Veyxyl LA $20 \%{ }^{\circledR}$ ), corticosteroids (Dexakel $0.2^{\circledR}$, KELA, Belgium) and antihistaminic drugs (Ahistin $10 \%{ }^{\circledR}$, VETERINA, Croatia) in doses recommended by the manufacturer's prescription.

The analysis of morphological characteristics of larves served to identify third stage larves of the species $H$. bovis. The diagnosed larvae were light to dark brown in color, around $28 \mathrm{~mm}$ in length, their body exhibited funnel-shaped stigmatic plates, and it was established that they had no spines on the tenth (second-last) segment. A certain number of larvae were already in the stage when they begin to leave the animal through the opening formed previously by their mouth claws.

The antibiotic treatment of the cow was continued for next six days. The cow tolerated the intervention well and recovered rapidly. At the next physical checkups 7 and 30 days after intervention the cow was very active and in good condition and there were no sign of parasitical relapses.

\section{DISCUSSION}

Diphtheroid species of the genus Hypoderma have major significance due to the fact that they can cause myiasis in humans which can clinically manifest in different ways. They can cause so-called creeping disease (myiasis linearis, a migrating line), due to the larva migrans which occurs when the larvae penetrates into the skin through the openings of the hair follicle and sweat glands, and then migrates under the skin, forming a pruritic erythematous line (9).

Lagace-Wiens et al. (10) reported about the first two diagnosed cases of internal ophthalmomyiasis in humans in Canada, caused by the species $H$. tarandi. Infections of humans by the species $H$. tarandi are very rare and still not clarified to a sufficient degree. Both species (H. bovis and $H$. Lineatum) can cause infections in humans, and they are distributed in different areas of North America, Europe and Asia (3, 4, 7, 11). The third species that parasitizes in cattle and yaks in China
(H. sinense), can also be responsible for cases of infestation among the human population (10).

In the past century, the occurence of bovine hypodermosis in certain European countries indicates high prevalence: Slovakia (80\%), Greece $(49.2 \%)$, Italy $(85 \%)$, Spain $(52.3 \%)$, Great Britain $(40 \%)$, and in Romania $(32-42 \%)$ (12, 13). In southwestern Spain, the maximum annual temperatures are $20-21^{\circ} \mathrm{C}$, the maximum summer temperatures are $29-30^{\circ} \mathrm{C}$, which favors faster development and earlier appearance of the disease in the course of the year $(7,17)$.

Otranto et al. reported about the presence and spreading of hypodermosis in cattle in Albania, underscoring that this country poses a risk for the spreading of hypodermosis into other European countries (6). In the past 50 years, hypodermosis has been successfully eradicated in many countries of Northern Europe, such as Denmark, the Netherlands, the Czech Republic, Germany, France, and Switzerland (6).

France is one of the European countries that have introduced a programme for the eradication of hypodermosis, and in order for its effect to be satisfactory it is necessary that such programmes encompass larger epizootiological areas (13). Haine et al. presented data on the regional prevalence of hypodermosis in cattle in Belgium, which stood at $36-92 \%$ (15). Such a high prevalence of infection was conditioned by the size of the pastures and the effects of various relevant climatic factors (daily temperature, precipitation and relative humidity) $(13,14,15,16)$. The latest investigations conducted in Romania showed that, based on clinical examinations, the prevalence of hypodermosis was $16.21 \%$, on parasitological section, $18.91 \%$, while the seroprevalence was $27.27 \%$ (13).

This report of a diagnosed case is one of the few registered cases of hypodermosis in cattle in Serbia, but the first documented case in Vojvodina (Northern Serbia). The circulation of humans and goods, the transportation and acquiring of animals, create preconditions for the introduction of new sources of infection and the maintenance of this disease. The disease is mostly present in Central and Southern Serbia, in cattle that are kept in pasture during the summer and are outdoor rearing. Under such breeding conditions, cattle grub parasitize under the cattle's skin during the period from February to September. Since new infections can begin already in June, the same animal can become infected with two generations of larvae during the period from June to August (18). Since the animal in this case report is one that was purchased, it is clear that it had already been infected upon its introduction to the new herd. 
Having in mind the geo-climatic characteristics of the region of Southern Serbia and the type of cattle breeding maintained in this locality, an even higher prevalence of cattle infection with cattle grub could be expected. The risk for the spread of this disease in Serbia is even further increased when one takes into consideration the close proximity of certain countries in this region (Greece, Albania, Romania, Turkey) in which hypodermosis in cattle is present $(6,13)$.

The clinical finding of $H$. bovis in a young ox from the territory of the Nišava District in 2006 and the finding in a parasitological section in a young ox from the territory of the Braničevo district in 2007 are individual cases recorded in Central and Southern Serbia by field veterinarians (18).

Due to its influence on meat, milk and leather production, hypodermosis results in major economic losses and it can also yield a negative effect on the general health condition and the immunological status of the diseased animals' organism (19). The implementation of efficient prophylactic measures against this disease is successfully controlled at national level in many European countries (4, 13, $14,15)$.

There is no systematized data in Serbia on the prevalence of hypodermosis infection in cattle, either along the slaughter lines or in the records of the authorized services. There is also no statistical data available from the Serbian leather industry on damage and losses caused by cattle grub. The individual cases established through clinical examinations of cattle or at parasitological sections indicate the need for more detailed investigations and the keeping of records for each diagnosed case in order to establish the real incidence of hypodermosis in cattle in certain regions of Serbia. Such an approach is also of paramount epizootiological importance for the other countries of South-Eastern Europe surrounding Serbia (Croatia, Slovenia, Bosnia-Herzegovina, Romania, Bulgaria, Macedonia, Montenegro, and Albania).

\section{ACKNOWLEDGEMENT}

This paper was realized within the Project „Monitoring of game health and introduction of new biotechnological procedures in the detection of infectious and zoonotic agents - risk analysis regarding the health of humans, domestic and wild animals and environmental contamination" (Number TR31084) and Project „Implementation of EIIP/ISM bioinformatic platform in discovery of new therapeutic targets and potential therapeutic molecules“ (Number 173001), financed by the Ministry of Education and Science of the Republic of Serbia.

132

\section{REFERENCES}

1. Zumpt, F. (1965). Myiasis in man and animals in the old world. Butter-worths. London, U.K., 217-229.

2. Plesek, T. (1926). Revue des especes palearctiques des Oestridae et catalogue raisonne de leur collection au Musee zoologique de 1' academiedes Sciences. Annals Museum Zoology of Leningrad 24, 215.

3. Otranto, D., Traversa, D., Colwell, DD., Guan, G., Giangaspero, A., Boulard, C., Yin H. (2004). A third species of Hypoderma (Diptera: Oestridae) affecting cattle and yaks in China: molecular and morphological evidence. J Parasitol. 90, 958-965.

http://dx.doi.org/10.1645/GE-232R

PMid: 15562593

4. Hassan, M., Khan, N.M., Abubakar, M., Waheed, H.M., Iqbal, Z., Hussain, M. (2010). Bovine hypodermosis - a global aspect. Trop Anim Health Prod. 42, 1615-1625. http://dx.doi.org/10.1007/s11250-010-9634-y PMid:20607401

5. Gorcea, C.F., Calescu, N., Gherman, M.C., Mihalca, D.A., Cozma, V. (2011). Diagnostic values of clinical, pathological and serologic findings in cattle hypodermosis in Peştişani, Gorj County Romania. Sci Parasitol. 12, 173-176.

6. Otranto, D., Zalla, P., Testini, G., Zanaj, S. (2005). Cattle grub infestation by Hypodema sp. in Albania and risk for European countries. Vet Parasitol. 28, 157-162. http://dx.doi.org/10.1016/j.vetpar.2004.11.016 PMid:15725546

7. Ahmed, H., Khan, M. R., Panadero-fontan, R., Sandez, C. L., Farooq, M., Naqvi, SMS., Qayyum, M. (2012). Geographical distribution of hypodermosis (Hypoderma sp.) in Northern Punjab, Pakistan. Kafkas Univ. Vet. Fak. Derg. 18 (Suppl-A): A2151219

8. Capinera, J.L. (2008). Encyclopedia of entomology. 2nd Edition. Vol. 1-4. Springer, Dordrecht, The Netherlands http://dx.doi.org/10.1007/978-1-4020-6359-6

9. Van Hal, S.J.M., Hudson, B.J., Wong, D.A. (2004). Furuncular myiasis after contact with clothing (when washing clothes can be infectious). Clin Infect Dis. 39, 1552-1553.

http://dx.doi.org/10.1086/425505

PMid:15546103

10. Derraik, J.G.B., Hetah, A.C.G., Redemaker, M. (2010). Human myasis in New Zealand: imported and indiginously-acquired cases; the species of concern and clinical aspects. NZ Med J. 123, 1322. 
11. Lagace-Wiens, P.R.S., Dookeran, R., Skinner, S., Leitch, R., Collwel, D.D., Galloway, D.T. (2008). Human ophthalmomyasis interna caused by Hypoderma tarandi, Northern Canada. Emerg Infect Dis. 14, 64-66.

http://dx.doi.org/10.3201/eid1401.070163

PMid:18258079 PMCid:PMC2600172

12. Anderson, J.R., (2006). Oestrid myiasis of humans. In: Colwell, D.D., Hall, M.J., Scholl, P.J. (Eds.) The oestrid flies biology, host-parasite relation'ships, impact and management (pp. 359). Oxford (UK): CABI Publishing.

http://dx.doi.org/10.1079/9780851996844.0201

13. O'Brien, D.J. (1998). Warble fy prevalence in Europe 1997 after COST 811. In: Boulard, C., Sol, J., Pithan, D., O’Brien, D.J., Webster, K., Sampimon, O.C. (Eds.), Improvements in the control methods for warble fy in livestock (pp. 20-23). European Commission. Brussels PMid:9510819

14. Boulard, C., Avinerie, M., Argente, G., Languille, J., Pagept, L., Petit, E. (2008). A successful, sustainable and low cost control-programme for bovine hypodermosis in France. Vet Parasitol. 158, 1-10. http://dx.doi.org/10.1016/j.vetpar.2008.07.026 PMid:18789582

15. Haine, D., Boelaert, F., Pfeiffer, D.U., Saegerman, C., Lonneux, J.F., Losson, B., Mintiens, K. (2004). Herdlevel seroprevalence and risk-mapping of bovine hypodermosis in Belgian cattle herds. Prev Vet Med. 65, 93-104. http://dx.doi.org/10.1016/j.prevetmed.2004.06.005 PMid:15454329
16. Khan, M. R., Ahmed, H., Panadero-fontan, R., Sandez, C. L., Farooq, M., Naqvi, SMS., Qayyum, M. (2015). Risk mapping of bovine hypodermosis by using Geographical Information System (GIS) in cattle of subtropical region, Pakistan. Journal of Infection in Developing Countries 9 (8): $872-877$.

http://dx.doi.org/10.3855/jidc.5387

PMid:26322880

17. Ahmed, H., Khan, M. R., Panadero-fontan, R., Mustafa, I., Sandez, C. L., Qayyum, M. (2013). Influence of epidemiological factors on the prevalence and intensity of Hypoderma sp. in cattle of Potowar Region, Pakistan. Pak. J. Zoo. 45 (6): 1495-1500.

18. Dimitrijević, S., Ilić, T. (eds) (2011). Clinical Parasithology. Faculty of Veterinary Medicine, University of Belgrade, Belgrade: Interprint D.O.O.

19. Khan, N.M., Iqbal, Z., Sajid, S.M., Anwar, M., Needham, R.G., Hassan, M. (2006). Bovine hypodermosis: Prevalence and economic significance in southern Punjab, Pakistan. Vet Parasitol. 141, 386-390.

http://dx.doi.org/10.1016/j.vetpar.2006.05.014

PMid:16787710 